\title{
ANALISIS KOMODITAS UNGGULAN DAN ARAHAN RENCANA PENGEMBANGANNYA DI KOTA PAGAR ALAM,PROVINSI SUMATERA SELATAN
}

Analysis of The Competitive Commodities and its Direction of Development Plan in Pagar Alam City, South Sumatera Province

\author{
Ahmad Zamhari ${ }^{1}$, Santun R.P. Sitorus ${ }^{2}$, Andrea Emma Pravitasari ${ }^{2}$
}

Diterima: 7 Desember 2016

Disetujui: 18 Agustus 2017

\begin{abstract}
Abstrak: Pengembangan komoditas unggulan secara terintegrasi pada suatu wilayah diharapkan dapat meningkatkan nilai tambah komoditas, pendapatan masyarakat dan perekonomian wilayah. Tujuan penelitian ini adalah untuk menganalisis komoditas unggulan, potensi pengembangan untuk komoditas unggulan, analisis hirarki wilayah dan arahan rencana pengembangan komoditas unggulan. Komoditas unggulan didapatkan dengan analisis Location Quotient (LQ) dan Shift Share Analysis (SSA). Lahan yang berpotensi pengembangandianalisis dengan arahan ketersediaan dan kesesuaian lahan serta sistem informasi geografis, Hiraki wilayah dengan analisis skalogram. Arahan rencana pengembangan komoditas unggulan ditetapkan berdasarkan pertimbangan lahan yang berpotensi pengembangan, hirarki wilayah, lahan yang kompak dan kebijakan pemerintah daerah. Hasil penelitian menunjukkan komoditas unggulan adalah kopi robusta, padi sawah dan kubis. Arahan pengembangan kopi robusta diprioritaskan di Kecamatan Dempo Selatan seluas 2,824.26 ha. Padi sawah diprioritaskan di Kecamatan Dempo Tengah seluas 1,496.13 ha. Pengembangan kubis tidak tersedia.
\end{abstract}

\section{Kata kunci: arahan pengembangan,komoditas unggulan, lahan berpotensi pengembangan}

\begin{abstract}
The Development of competitive commodities in a region are expected to improve added value of the commodities, to increase society income and to improve regional economic conditions. This study was conducted (1) to analyse competitive commodities of agriculture in each district, (2) to analyse potential land for competitive commodities development (3) to analyse regional hierarchies (4) to formulate direction of competitive commodities development plan. The competitive commodities were obtained using Location Quotient (LQ) and Shift Share Analysis (SSA). Analysis potential land for competitive commodities development was analysed using land availability and suitability and geographical information system. Regional hierarchy was analysed using schalogram method. Competitive commodities development direction considered based on potential land, regional hierarcy, compactness of land and local government policy. The results showed that competitive commodities in every district were coffee robusta, rice farming and cabbage. The direction development of coffee was given priority in South Dempo district area of 2,824.26 ha. Rice farming was given priority in Central Dempo district area of 1,496.13 ha. Meanwhile,development of cabbage is not available.
\end{abstract}

Keywords: competitive commodities, direction of development,potential land

\footnotetext{
${ }^{1}$ Program Studi Ilmu Perencanaan Wilayah, Sekolah Pascasarjana Institut Pertanian Bogor

${ }^{2}$ Divisi Perencanaan Pengembangan Wilayah, Institut Pertanian Bogor
} 


\section{PENDAHULUAN}

Sektor pertanian merupakan tumpuan kehidupan bagi mayoritas penduduk di Kota Pagar Alam. Pendapatan domestik regional bruto (PDRB) tahun 2015 menunjukkan bahwa sektor pertanian memberikan sumbangan terhadap PDRB terbesar yaitu $24 \%$ di ikuti sektor perdagangan sebesar 19\% dan sektor konstruksi sebesar $18 \%$. Berdasarkan kategori lapangan usaha maka sektor pertanian menyerap tenaga kerja terbesar yaitu sebesar 37.89\% (BPS Kota Pagar Alam, 2015). Sektor pertanian di Kota Pagar Alam masih terkonsentrasi pada kegiatan on farm (budidaya). Komoditas perkebunan utama yaitu kopi robusta, hasil produksi mentahnya langsung di pasarkan ke Provinsi Lampung. Komoditas tanaman pangan utama yaitu padi sawah yang surplus setiap tahunnya dipasarkan ke Kota Palembang dan komoditas hortikultura seperti wortel, kubis dan cabe merah dipasarkan ke Kota Palembang.

Sektor utama atau sektor primer yang berbasis pertanian di Kota Pagar Alam perlu ditingkatkan nilai tambahnya agar perekonomian masyarakat meningkat. Salah satu upaya yang dapat dilakukan adalah dengan mengembangkan komoditas unggulan. Komoditas unggulan merupakan komoditas yang memiliki nilai strategis berdasarkan pertimbangan fisik (kondisi tanah dan iklim), sosial ekonomi dan kelembagaan (penguasaan teknologi, kemampuan sumberdaya manusia, infrastruktur, kondisi sosial budaya) untuk dikembangkan di suatu wilayah (Sitorus et al. 2014).

Pendekatan komoditas unggulan dilandasi pada pendapat bahwa yang perlu dikembangkan di sebuah wilayah adalah kemampuan berproduksi dan menjual hasil produksi tersebut secara efisien dan efektif dengan menggunakan sumber daya lokal untuk diekspor dan menghasilkan kekayaan daerah serta penciptaan peluang kerja (Ameriyani, 2014). Dengan demikian perekonomian wilayah akan bergerak lebih cepat sehingga akan meningkatkan pendapatan masyarakat.

Penentuan kesesuaian lahan dengan persyaratan tumbuh tanaman sangat diperlukan terutama dalam perencanaan pengembangan komoditas pertanian (Boix dan Zinx, 2008). Pengembangan komoditas unggulan perlu memperhatikan ketersediaan lahan dan kesesuaian lahan. Pengembangan komoditas unggulan berdasarkan hasil evaluasi kesesuaian lahan akan menghasilkan pertumbuhan dan produksi sesuai dengan kelas kesesuaian lahannya. Arahan pengembangan komoditas unggulan perlu dilakukan agar pengembangan komoditas unggulan lebih terarah pada lahan-lahan yang berpotensi pengembangan.

Tujuan penelitian ini adalah (1) Menganalisis komoditas unggulan di tiap kecamatan (2) Menganalisis lahan yang berpotensi pengembangan untuk komoditas unggulan, (3) Menganalisis hirarki wilayah, (4) Menyusun arahan rencana pengembangan komoditas unggulan.

\section{METODE}

\section{Lokasi dan Waktu Penelitian}

Penelitian dilaksanakan di Kota Pagar Alam, Provinsi Sumatera Selatan yang secara

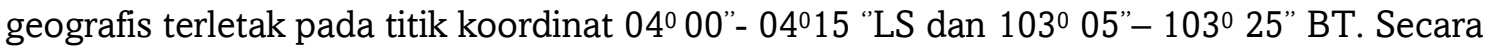
administratif Kota Pagar Alam terdiri dari 5 kecamatan yaitu Kecamatan Dempo Selatan, Dempo Tengah, Dempo Utara, Pagar Alam Selatan dan Pagar Alam Utara (Gambar 1). Penelitian dilaksanakan pada bulan Maret 2016 sampai dengan Oktober 2016. 


\section{Jenis Data dan Alat}

Data yang digunakan dalam penelitian ini berupa data sekunder dan data primer. Data sekunder berupa luas tanam komoditas perkebunan tahun 2010-2015, luas panen komoditas tanaman pangan dan hortikultura tahun 2010-2015, Jumlah keluarga pertanian, satuan peta tanah skala 1:250,000, citra spot 6 tahun 2015, peta administrasi Kota Pagar Alam skala 1:250,000, peta RTRW Kota Pagar Alam skala 1:250,000, peta penggunaan lahan tahun 2012 yang diedit dengan citra spot 6 tahun 2015, peta kawasan hutan, peta ketinggian, peta temperatur, data curah hujan, peta kontur, peta tekstur tanah, peta kedalaman tanah,salinitas, peta kelas lereng, jumlah penduduk, fasilitas pendidikan, fasilitas kesehatan, fasilitas perekonomian, sarana dan produksi pertanian.

Data primer diperoleh dari survei dan wawancara. Survei dilakukan untuk memvalidasi lokasi eksisting komoditas unggulan. Wawancara dilakukan melalui wawancara semi terstruktur dengan ketua kelompok tani yaitu $10 \%$ dari kelompok tani untuk analisis usahatani dengan teknik Purposive Sampling. Alat yang digunakan berupa Global Positioning System, komputer dengan softwareMS-Office 2010 dan sistem informasi geografis.

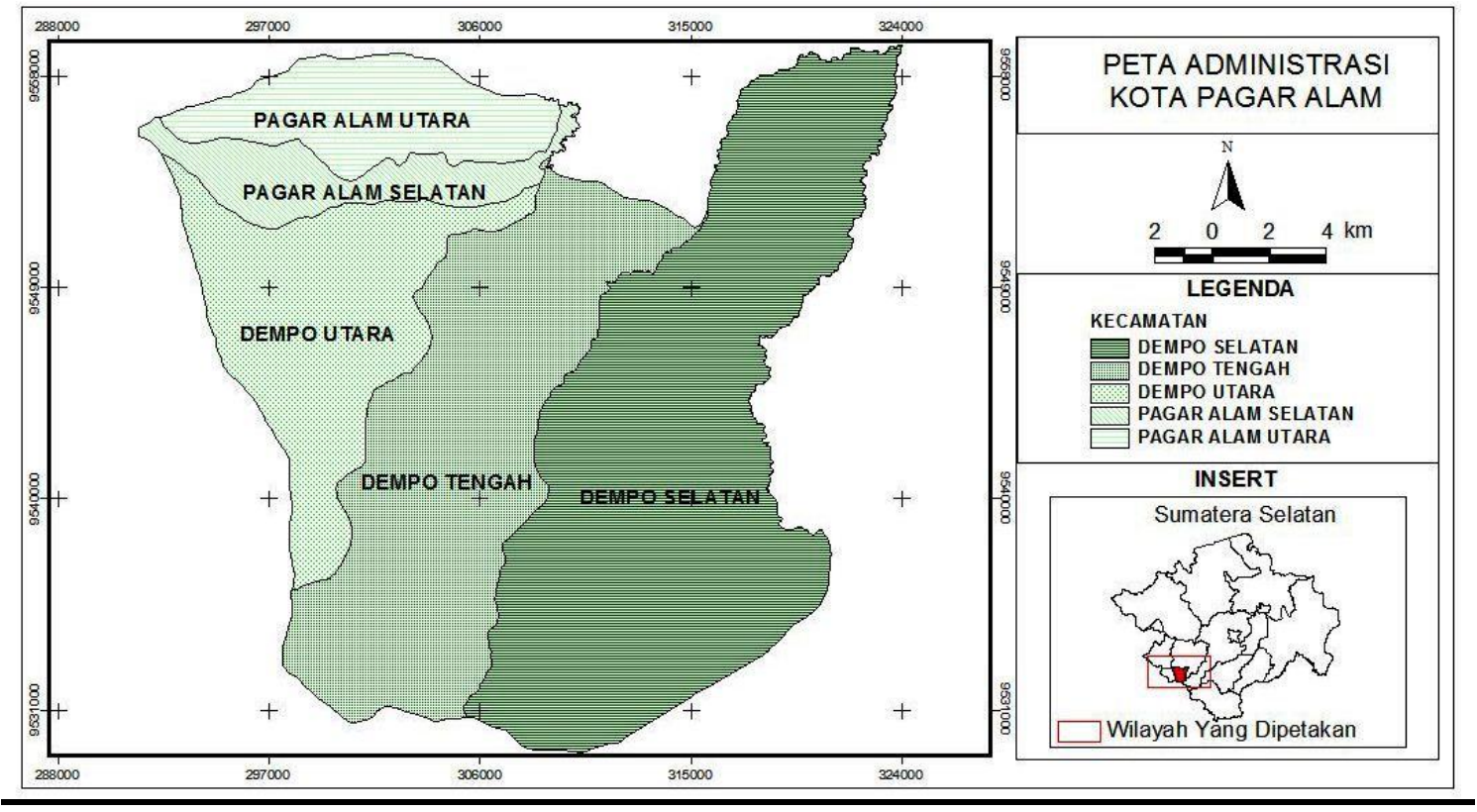

Gambar 1. Peta Administrasi Kota Pagar Alam

\section{ANALISIS}

\section{Identifikasi Komoditas Unggulan di Setiap Kecamatan}

Komoditas unggulan ditentukan dengan metode location quotient (LQ) dan Shift Share Analysis (SSA). LQ merupakan metode yang efisien untuk menentukan konsentrasi komoditas di beberapa wilayah dan kemudian pembuat kebijakan atau peneliti dapat merencanakan atau mengevaluasi pertumbuhan suatu wilayah (Chiang, 2008). Komoditas unggulan adalah komoditas yang memiliki nilai LQ $>1$ dan komponen SSA diffrential shift (DS) positif. Metode ini sudah banyak digunakan dalam berbagai penelitian, antara lain 
Manik et al (2013), Yustian et al. (2014), Raharjo et al. (2015), Setiawati et al. (2016). Rumus LQ yang digunakan menurut Blakely(1994) adalah

Dimana :

$$
L Q_{i j}=\frac{X_{i j} / X_{i .}}{X_{. j} / X_{. .}}
$$

$L Q_{i j} \quad$ : Nilai LQ untuk komoditas ke-j di kecamatan ke-i di Kota Pagar Alam

$X_{i j} \quad:$ Komoditas ke-j di kecamatan ke-i di Kota Pagar Alam

$X_{i .} \quad:$ Jumlah komoditas di kecamatan ke-i di Kota Pagar Alam

$X_{. j} \quad:$ Komoditas ke-j di Kota Pagar Alam

$X_{. .} \quad$ : Jumlah komoditas di Kota Pagar Alam

Rumus SSA yang digunakan adalah

$$
\mathrm{SSA}=\left(\frac{X . .(t 1)}{X . .(t 0)}-1\right)+\left(\frac{X . j(t 1)}{X . j(t 0)}-\frac{X . .(t 1)}{X . .(t 0)}\right)+\left(\frac{X i j(t 1)}{X i j(t 0)}-\frac{X . j(t 1)}{X . j(t 0)}\right)
$$

a $\quad b$

C

Dimana :

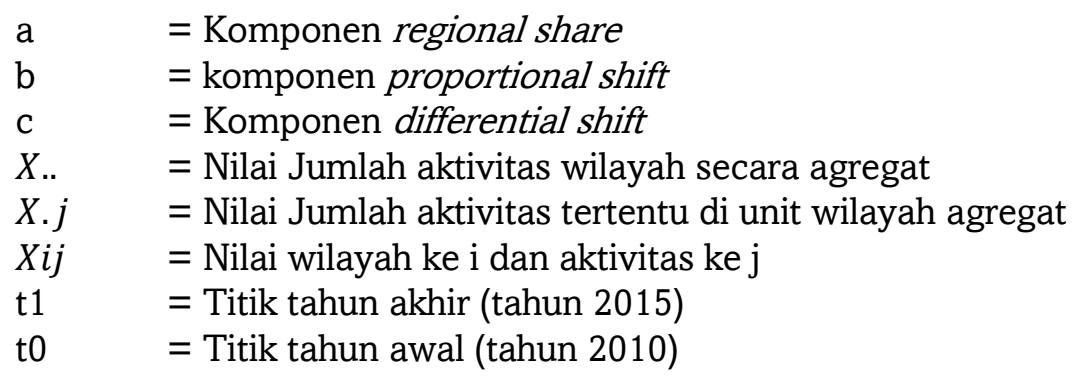

\section{Analisis Ketersediaan Lahan}

Ketersediaan lahan dianalisis dengan mengoverlay satuan peta tanah dengan peta kawasan hutan lindung, peta RTRW Kota Pagar Alam tahun 2012-2032 (peta pola ruang, peta kawasan strategis), peta penggunaan lahan. Kawasan hutan lindung dan kawasan strategis dikeluarkan dari satuan peta tanah. Peta pola ruang yang dipertahankan adalah peruntukan untuk perkebunan dan pertanian. Peruntukan untuk pertanian kemudian di bagi lagi menjadi peruntukan untuk tanaman pangan dan hortikultura.

\section{Analisis Kesesuaian Lahan Untuk Komoditas Unggulan}

Penilaian kelas kesesuaian lahan dilakukan pada lahan-lahan yang tersedia dengan cara membandingkan persyaratan yang dibutuhkan oleh komoditas unggulan yang akan dikembangkan dengan karakteristik atau kualitas lahan yang dimilki oleh lahan yang akan digunakan (FAO 1976). Analisis kesesuaian lahan dilakukan pada peta lahan yang tersedia dengan analisis sistem informasi geografis. Metode ini sudah banyak digunakan dalam berbagai penelitian, antara lain Wirosoedarmo et al. (2011), Ogunlade et al. (2012), Widiatmaka et al. (2014), Yanis et al. (2014) dan Nowar et al. (2015). Analisis dilakukan dengan metode overlay antara peta satuan tanah, peta temperatur, peta curah hujan, peta kelas lereng, peta tekstur tanah, peta kedalaman tanah, peta bahaya erosi, kerawanan banjir dan salinitas. Kriteria Kesesuaian lahan yang digunakan mengunakan kriteria dari Balai Besar Penelitian dan Pengembangan Sumberdaya Lahan Pertanian tahun 2011 (BBPPSDLP,2011). 
Lahan Yang Berpotensi Pengembangan Untuk Komoditas Unggulan

Lokasi eksisting komoditas unggulan didapatkan dari proses digitasi visual on screen citra spot 6 liputan tahun 2015 menggunakan sistem informasi geografis dan divalidasi dengan survei menggunakan GPS. Digitasi visual dilakukan menurut pola, rona, warna dan asosiasi (Lillesand dan Kiefer, 1993). Potensi pengembangan komoditas unggulan di dapatkan dari hasil lahan yang tersedia dan sesuai dikurangi (di overlay) dengan lokasi eksisting komoditas unggulan

\section{Analisis Hirarki Wilayah}

Hirarki wilayah tiap kecamatan ditentukan dengan metode skalogram mengikuti Panuju dan Rustiadi (2013) dan Sitorus et al (2015). Dengan menggunakan metode ini semua jumlah penduduk, fasilitas pendidikan, fasilitas kesehatan, fasilitas ekonomi, fasilitas pertanian, dicatat dalam bentuk matriks dan dihitung berdasarkan indeks perkembangan kecamatan (IPK). IPK dikelompokkan ke dalam tiga kelas hirarki, yaitu kelas hirarki I (tinggi), kelas hirarki II (sedang) dan kelas hirarki III (rendah). Penentuannya didasarkan atas nilai standar deviasi IPK (St dev), nilai rataan IPK, dan nilai rataan IPK dijumlah dengan dua kali nilai standar deviasinya.

\section{Arahan Rencana Pengembangan komoditas unggulan}

Arahan rencana pengembangan komoditas unggulan dilakukan berdasarkan pertimbangan lahan yang berpotensi pengembangan paling luas, kelas kesesuaian lahan paling tinggi, lahan yang kompak, kelas hirarki wilayah kecamatan paling tinggi dan arahan kebijakan pemerintah daerah. Arahan rencana pengembangan komoditas unggulan dipetakan dengan menggunakan sistem informasi geografis

\section{HASIL DAN PEMBAHASAN}

\section{Identifikasi Komoditas Unggulan}

Komoditas unggulan merupakan komoditas yang memiliki nilai strategis berdasarkan pertimbangan fisik (kondisi tanah dan iklim) maupun sosial ekonomi dan kelembagaan (penguasaan teknologi, kemampuan sumberdaya manusia, infrastruktur, kondisi sosial budaya) untuk dikembangkan pada suatu wilayah (Sitorus et al. 2014). Data yang digunakan untuk menentukan komoditas unggulan adalah data luas tanam (ha) untuk komoditas perkebunan, luas panen (ha) untuk komoditas tanaman pangan dan hortikultura tahun 2010-2015. Hasil identifikasi komoditas unggulan tanaman perkebunan, tanaman pangan dan tanaman hortikultura di sajikan pada Tabel 1.

Berdasarkan Tabel 1 didapatkan bahwa Kecamatan Dempo Tengah memiliki banyak jenis komoditas unggulan perkebunan dan pangan sedangkan Kecamatan Dempo Utara memiliki banyak jenis komoditas unggulan tanaman pangan dan hortikultura. Kecamatan Pagar Alam Selatan tidak memiliki komoditas unggulan karena merupakan pusat kota, pemukiman dan pemerintahan. Kecamatan yang hanya memiliki satu komoditas unggulan ditetapkan sebagai komoditas unggulan utama, kecamatan yang memiliki lebih dari satu komoditas unggulan maka pemilihan komoditas unggulan utama ditetapkan berdasarkan kriteria (1) jumlah petani paling banyak (2) Keuntungan usaha tani paling tinggi (3) luas 
tanam/luas panen paling besar dan (4) sistem pengelolaan monokultur. Komoditas unggulan utama dan penunjang disajikan pada Tabel 2.

Tabel 1. Hasil Analisis Komoditas Unggulan di Kota Pagar Alam

\begin{tabular}{|c|c|c|c|c|}
\hline \multirow{2}{*}{ No } & \multirow{2}{*}{ Kecamatan } & \multicolumn{3}{|c|}{ Komoditas Unggulan } \\
\hline & & Perkebunan & Pangan & Hortikultura \\
\hline 1 & Dempo Selatan & kopi robusta & padi sawah & - \\
\hline 2 & Dempo Tengah & $\begin{array}{l}\text { kopi robusta, cengkeh, } \\
\text { kemiri, kayu manis }\end{array}$ & $\begin{array}{l}\text { padi sawah, ubi jalar, } \\
\text { jagung }\end{array}$ & - \\
\hline 3 & Dempo Utara & kopi robusta & $\begin{array}{l}\text { padi sawah,kacang } \\
\text { tanah, jagung }\end{array}$ & $\begin{array}{l}\text { kubis, wortel, tomat, } \\
\text { buncis }\end{array}$ \\
\hline 4 & Pagar Alam Selatan & - & - & - \\
\hline 5 & Pagar Alam Utara & $\begin{array}{l}\text { kopi robusta, kayu } \\
\text { manis }\end{array}$ & $\begin{array}{l}\text { padi sawah, kacang } \\
\text { tanah }\end{array}$ & - \\
\hline
\end{tabular}

Tabel 2. Komoditas Unggulan Utama dan Penunjang di Kota Pagar Alam

\begin{tabular}{|c|c|c|c|}
\hline \multirow{2}{*}{ No } & \multirow{2}{*}{ Kecamatan } & \multicolumn{2}{|c|}{ Komoditas Unggulan } \\
\hline & & Utama & Penunjang \\
\hline \multicolumn{4}{|c|}{ Tanaman Perkebunan } \\
\hline 1 & Dempo Selatan & kopi robusta & - \\
\hline 2 & Dempo Tengah & kopi robusta & cengkeh, kemiri, kayu manis,lada \\
\hline 3 & Dempo Utara & kopi robusta & - \\
\hline 4 & Pagar Alam Selatan & - & - \\
\hline 5 & Pagar Alam Utara & kopi robusta & kayu manis \\
\hline \multicolumn{4}{|c|}{ Tanaman Pangan } \\
\hline 1 & Dempo Selatan & padi sawah & - \\
\hline 2 & Dempo Tengah & padi sawah & ubi jalar, jagung \\
\hline 3 & Dempo Utara & padi sawah & Jagung \\
\hline 4 & Pagar Alam Selatan & - & - \\
\hline 5 & Pagar Alam Utara & padi sawah & kacang tanah \\
\hline \multicolumn{4}{|c|}{ Tanaman Hortikultura } \\
\hline 1 & Dempo Selatan & - & - \\
\hline 2 & Dempo Tengah & - & - \\
\hline 3 & Dempo Utara & Kubis & wortel, tomat, buncis,labu siam \\
\hline 4 & Pagar Alam Selatan & - & - \\
\hline 5 & Pagar Alam Utara & - & - \\
\hline
\end{tabular}

Berdasarkan Tabel 2 didapatkan bahwa komoditas unggulan utama untuk tanaman perkebunan di Kecamatan Dempo Selatan, Dempo Tengah, Dempo Utara dan Pagar Alam Utara adalah kopi robusta. Komoditas unggulan untuk tanaman pangan di Kecamatan Dempo Selatan, Dempo Tengah, Dempo Utara dan Pagar Alam Utara adalah padi sawah. Komoditas unggulan utama tanaman hortikultura di Kecamatan Dempo Utara adalah kubis. Komoditas unggulan penunjang bervariasi di tiap kecamatan.

\section{Ketersediaan Lahan}

Ketersediaan lahan untuk pengembangan komoditas unggulan pertanian dan perkebunan di Kota Pagar Alam masih sangat besar. Hasil analisis sistem informasi geografis menunjukkan ketersediaan lahan untuk perkebunan seluas 23,561.57 ha dan 
untuk pertanian seluas 4,141.82 ha. Dari alokasi ketersediaan lahan untuk pertanian Pemerintah Kota Pagar Alam menetapkan Kecamatan Dempo Utara sebagai wilayah pengembangan hortikultura dan selebihnya untuk pengembangan tanaman pangan. Dengan demikian ketersediaan lahan untuk hortikultura seluas 179.56 ha, tanaman pangan seluas 3,962.26 ha dan perkebunan seluas 23,561.57 ha.Peta ketersediaan lahan disajikan pada Gambar 2.

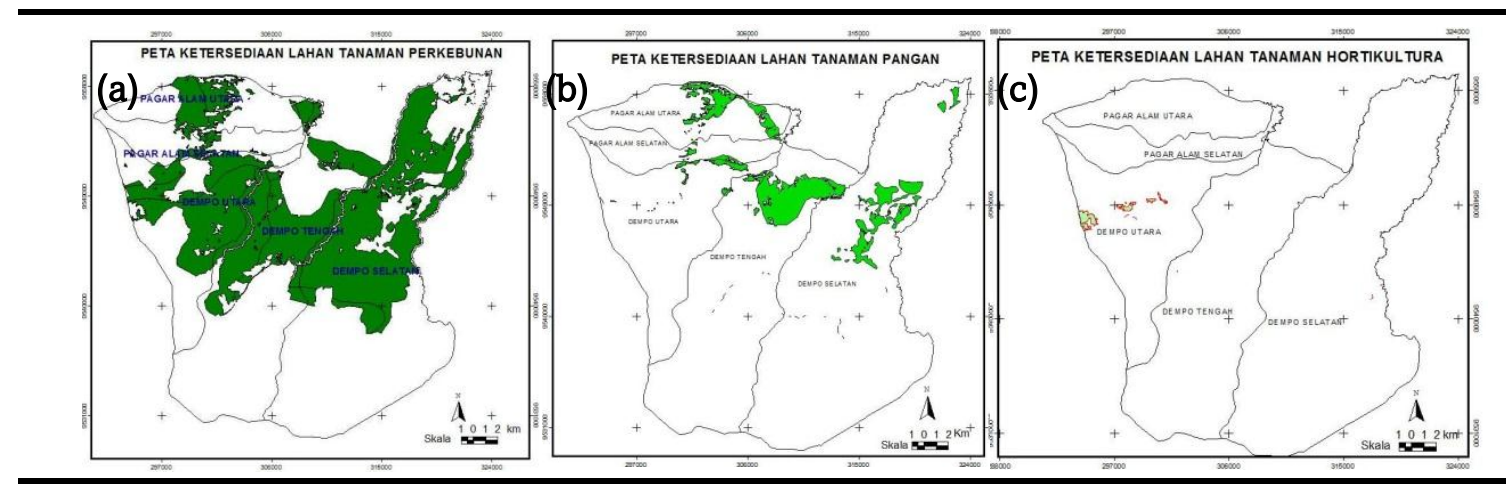

Gambar 2. Ketersediaan Lahan (a) kopi robusta (b) padi sawah (c) kubis

\section{Kesesuaian Lahan}

Analisis kesesuaian lahan dilakukan pada lahan-lahan yang tersedia menurut komoditas unggulan utama (kopi robusta, padi sawah dan kubis) di masing-masing kecamatan sesuai dengan komoditas unggulan utamanya. Hasil analisis kesesuaian lahan disajikan pada Tabel 3 .

Tabel 3. Kesesuaian Lahan Komoditas Unggulan

\begin{tabular}{llllrr}
\hline Komoditas & Kelas & Sub Kelas & Faktor Pembatas & Luas (ha) & $\%$ \\
\hline Kopi & S1 & & - & - & - \\
& S2 & S2rc & Tekstur & 91.42 & 0.39 \\
& & S2warc & bulan kering, tekstur & $7,606.71$ & 32.28 \\
& S3 & S3wa & bulan kering & $4,269.71$ & 18.12 \\
& & S3oa & Drainase & 499.63 & 2.12 \\
& & S3tc & temperatur & $5,531.50$ & 23.48 \\
& & S3eh & kelas lereng & 182.68 & 0.78 \\
& & S3waoa & bulan kering, drainase & 156.00 & 0.66 \\
& & S3waeh & bulan kering, kelas lereng & 100.31 & 0.43 \\
& & S3oaeh & drainase, kelas lereng & 5.90 & 0.03 \\
& S3tcoa & temperatur, drainase & 38.82 & 0.16 \\
& & S3tceh & temperatur,kelas lereng & 387.31 & 1.64 \\
& & S3tcwa & temperatur, bulan kering & $4,309.87$ & 18.29 \\
& & S3tcwaoa & temperatur, bulan kering,drainase & 77.50 & 0.33 \\
& & S3tcwaeh & temperatur, bulan kering,kelas lereng & 151.91 & 0.64 \\
& & Ntc & temperatur & 152.5 & 0.65 \\
\hline
\end{tabular}




\begin{tabular}{|c|c|c|c|c|c|}
\hline Komoditas & Kelas & Sub Kelas & Faktor Pembatas & Luas (ha) & $\%$ \\
\hline \multirow[t]{8}{*}{ Padi sawah } & S1 & - & - & - & - \\
\hline & S2 & S2tc & temperatur & 302.41 & 7.63 \\
\hline & & S2tceh & temperatur, kelas lereng & 6.40 & 0.16 \\
\hline & & S2tcehoa & temperatur, kelas lereng, drainase & 20.93 & 0.53 \\
\hline & S3 & S3tc & temperatur & $2,326.90$ & 58.73 \\
\hline & & S3tceh & temperatur, kelas lereng & $1,187.31$ & 29.97 \\
\hline & $\mathrm{N}$ & Neh & kelas lereng & 91.20 & 2.30 \\
\hline & & Ntc & temperatur & 27.11 & 0.68 \\
\hline Jumlah & & & & $3.962,26$ & 100 \\
\hline \multirow[t]{4}{*}{ Kubis } & S1 & & - & 37.23 & 20.73 \\
\hline & S2 & S2ehrc & kelas lereng, kedalaman tanah & 38.70 & 21.55 \\
\hline & S3 & S3renr & Tekstur & 21.32 & 11.87 \\
\hline & & S3ehwarcnr & kelas lereng, curah hujan, tekstur tanah & 82,31 & 45.84 \\
\hline Jumlah & & & & 179,56 & 100 \\
\hline
\end{tabular}

Keterangan $S 1=$ sangat Sesuai, $S 2=$ cukup sesuai, $S 3=$ sesuai marginal, $N=$ tidak sesuai
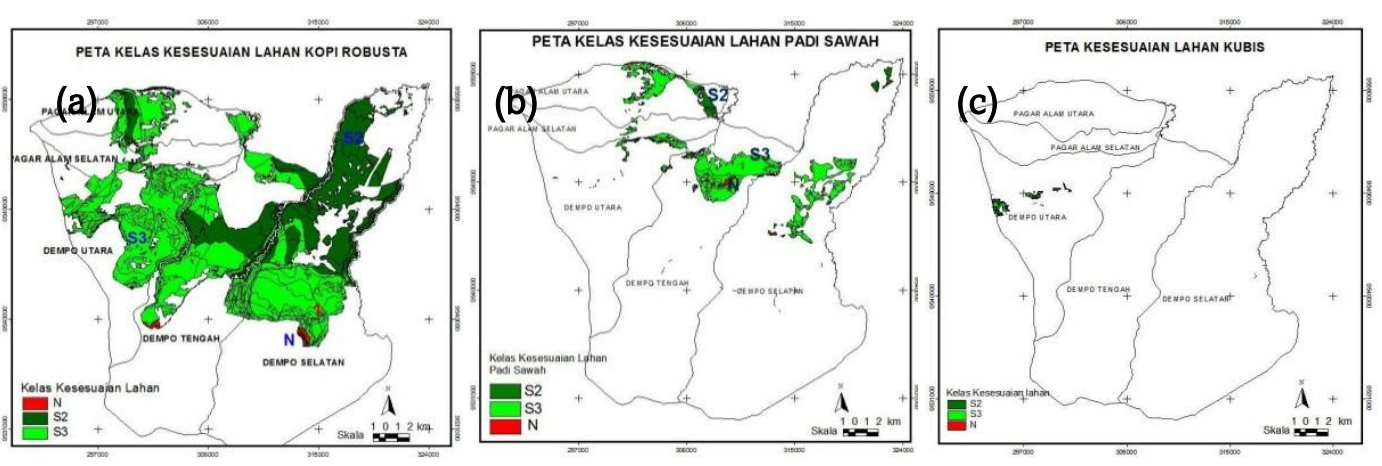

Gambar 3. Kelas Kesesuaian Lahan (A) Kopi Robusta (B) Padi Sawah (C) Kubis

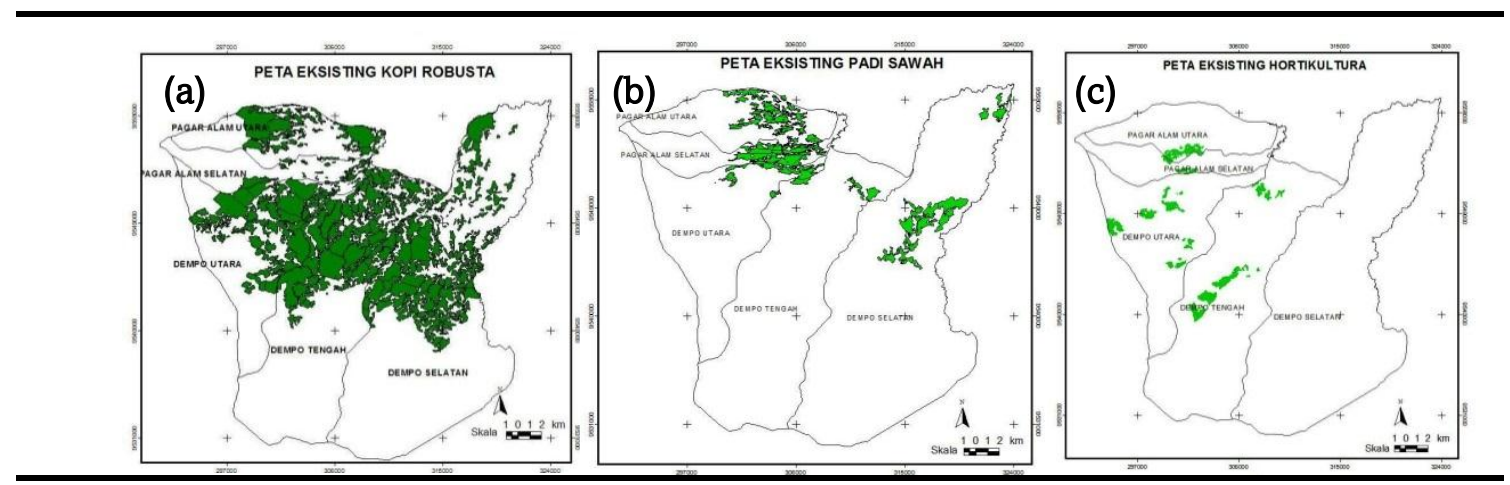

Gambar 4.Peta Eksisting(A) Kopi Robusta (B) Padi Sawah (C) Kubis 
Berdasarkan Tabel 3 didapatkan bahwa luas kesesuaian lahan untuk kopi robusta tergolong kelas kesesuaian S3 seluas 15,711.12 ha dan S2 seluas 7,698.13 ha. Lahan yang tidak sesuai $(\mathrm{N})$ dengan faktor pembatas temperatur tidak dapat dikembangkan. Kesesuaian lahan untuk komoditas padi sawah luas paling besar adalah kelas kesesuaian lahan S3 sebesar 3,514.21 ha dan S2 seluas 329.74 ha. Kesesuaian lahan untuk kubis yang terbesar adalah S3 dengan luas 103.63 ha, S2 seluas 38.70 ha dan S1 seluas 37.23 ha.Peta kelas kesesuaian lahan disajikan pada Gambar 3.

\section{Lahan Yang Berpotensi Pengembangan Untuk Komoditas Unggulan}

Lahan yang berpotensi pengembangan untuk komoditas unggulan diperlukan untuk mengidentifikasi lahan yang berpotensi untuk ekstensifikasi. Lahan yang berpotensi pengembangan didapatkan dari peta kesesuaian lahan komoditas unggulan (Gambar 3) dikurangi peta eksisting komoditas unggulan (Gambar 4). Lahan yang berpotensi untuk pengembangan komoditas unggulan disajikan pada Gambar 5.

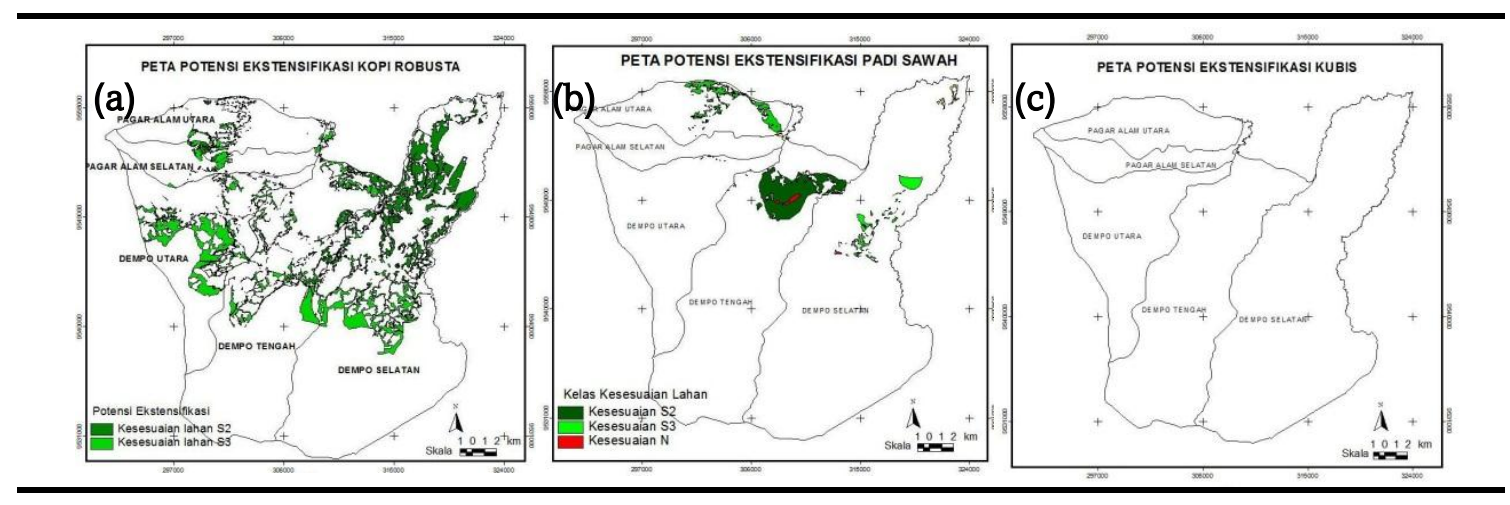

\section{Gambar 5. LahanYang Berpotensi Untuk Pengembangan(a) kopi robusta (b) padi sawah (c) kubis}

Lahan yang berpotensi pengembangan komoditas unggulan untuk kegiatan ekstensifikasi kopi robusta dan padi sawah masih sangat besar. Lahan yang berpotensi pengembangan untuk kopi robusta seluas 7,443.08 ha, terdiri dari 3,027.34 ha kelas kesesuaian S2 dan 4,415.74 ha kelas kesesuaian S3. Lahan yang berpotensi pengembangan untuk padi sawah seluas 2,350.89 ha, terdiri dari 225.82 ha kelas kesesuaian S2 dan $2,125.07$ ha kelas kesesuaian S3. Komoditas kubis tidak memiliki lahan potensial untuk kegiatan ekstensifikasi. Lahan yang berpotensi pengembangan untuk komoditas unggulan kopi robusta dan padi sawah disajikan pada Tabel 4.

Tabel 4. Lahan Yang Berpotensi Pengembangan Untuk Komoditas Ungulan di Kota Pagar Alam

\begin{tabular}{|c|c|c|c|c|c|c|c|c|}
\hline \multicolumn{5}{|c|}{ Kopi Robusta } & \multicolumn{4}{|c|}{ Padi Sawah } \\
\hline \multirow{2}{*}{\multicolumn{2}{|c|}{ Kecamatan }} & $\begin{array}{c}\text { Kesesuaia } \\
\text { n S2 }\end{array}$ & $\begin{array}{c}\text { Kesesuai } \\
\text { an S3 }\end{array}$ & \multirow[t]{2}{*}{$\begin{array}{c}\text { Jumlah } \\
\text { (ha) }\end{array}$} & \multirow[t]{2}{*}{ Kecamatan } & $\begin{array}{c}\text { Kesesuaian } \\
\text { S2 } \\
\end{array}$ & $\begin{array}{c}\text { Kesesuaian } \\
\text { S3 }\end{array}$ & \multirow[t]{2}{*}{$\begin{array}{c}\text { Jumlah } \\
\text { (ha) }\end{array}$} \\
\hline & & Luas (ha) & Luas (ha) & & & Luas (ha) & Luas (ha) & \\
\hline \multicolumn{2}{|c|}{ Dempo Selatan } & $2,549.21$ & $1,298.51$ & $3,847.72$ & Dempo Selatan & 42.91 & 331.93 & 374.84 \\
\hline \multicolumn{2}{|c|}{ Dempo Tengah } & 401.20 & 944.30 & $1,345.5$ & Dempo Tengah & 0 & $1,438.91$ & $\begin{array}{r}1,438.9 \\
1\end{array}$ \\
\hline \multicolumn{2}{|c|}{ Dempo Utara } & 0 & $1,475.42$ & $1,475.42$ & Dempo Utara & 0 & 23.10 & 23.10 \\
\hline $\begin{array}{l}\text { Pagar } \\
\text { Selatan }\end{array}$ & Alam & 5.81 & 183.21 & $1,89.02$ & $\begin{array}{l}\text { Pagar } \\
\text { Selatan }\end{array}$ & 10.30 & 17.61 & 27.91 \\
\hline $\begin{array}{l}\text { Pagar } \\
\text { Utara }\end{array}$ & Alam & 70.92 & 294.20 & 365.12 & Pagar Alam Utara & 172.61 & 313.52 & 486.13 \\
\hline Jumlah & & $3,027.34$ & $4,415.74$ & $7,443.08$ & Jumlah & 225.82 & $2,125.07$ & $\begin{array}{l}2,350.8 \\
9\end{array}$ \\
\hline
\end{tabular}




\section{Hirarki Wilayah}

Hasil perhitungan skalogram terhadap lima kecamatan di Kota Pagar Alam didapatkan tiga kelas hirarki. Hirarki 1 (tinggi) dengan IPK lebih dari 25.07 merupakan wilayah kecamatan yang tingkat pelayanan dan perkembangan wilayahnya tinggi yaitu Kecamatan Pagar Alam Selatan. Hirarki 2 (sedang) dengan IPK sebesar 22.2-25.07 merupakan wilayah dengan tingkat perkembangan wilayah sedang yaitu Kecamatan Dempo Utara dan Dempo Selatan. Hirarki 3 (rendah) dengan IPK kurang dari 22.22 merupakan wilayah dengan tingkat perkembangan wilayah rendah yaitu Kecamatan Pagar Alam Utara dan Kecamatan Dempo Tengah.

\section{Arahan Pengembangan Komoditas Unggulan}

Arahan pengembangan komoditas unggulan untuk kopi robusta dilakukan berdasarkan pertimbangan luas lahan potensial terbesar, kelas kesesuaian lahan tertinggi, lahan yang kompak dan kelas hirarki wilayah kecamatan tertinggi. Arahan pengembangan padi sawah dilakukan berdasarkan pertimbangan kebijakan pemerintah daerah dalam pengembangan lahan padi sawah baru. Arahan pengembangan komoditas unggulan kopi robusta dan padi sawah disajikan pada Gambar 6.

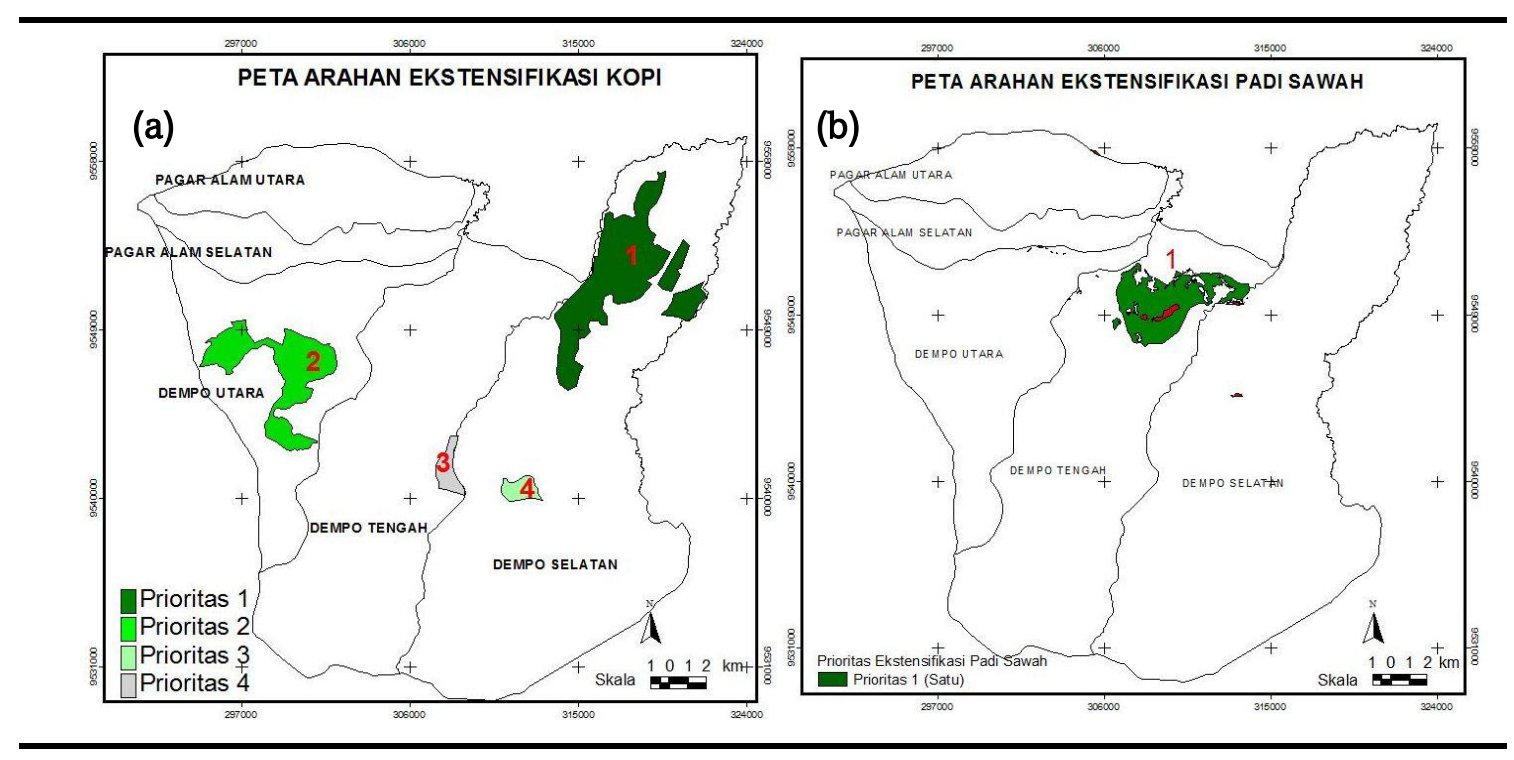

Gambar 6. Peta Arahan Pengembangan (a) kopi robusta (b) padi sawah

Pengembangan kopi robusta diarahkan di Kecamatan Dempo Selatan seluas 2,824.26 ha (Prioritas 1), Kecamatan Dempo Utara seluas 1,658.41 ha (Prioritas 2), Kecamatan Dempo Tengah seluas 241.41 ha (Prioritas 3) dan Kecamatan Dempo Selatan seluas 206.79 ha (Prioritas 4). Prioritas pengembangan lahan kopi robusta disajikan pada Tabel 5.

Tabel 5. Prioritas Pengembangan Lahan Kopi Robusta

\begin{tabular}{lllll}
\hline \multicolumn{1}{c}{ Kriteria } & \multicolumn{4}{c}{ Prioritas Pengembangan Lahan Kopi Robusta } \\
\hline & \multicolumn{1}{c}{1} & \multicolumn{1}{c}{2} & \multicolumn{1}{c}{4} \\
\hline Potensi lahan /luas lahan (ha) & $2,824.26$ & $1,658.41$ & 241.41 & 206.79 \\
Kelas Kesesuaian lahan & S2 & S3 & S3 & S3 \\
Kesatuan lahan & kompak & Kompak & kompak & kompak \\
Hirarki kecamatan & 2 & 3 & 3 & 2 \\
\hline
\end{tabular}

Keterangan S2=Cukup sesuai, S3=Sesuai marginal 
Arahan pengembangan padi sawah diprioritaskan sesuai dengan arahan kebijakan pemerintah Kota Pagar Alam untuk pengembangan lahan padi sawah baru di Kecamatan Dempo Tengah. Sehingga arahan pengembangan lahan padi sawah baru dilakukan di Kecamatan Dempo Tengah dengan luas 1,496.13 ha. Pengembangan komoditas unggulan kubis untuk pengembangan lahan baru sudah tidak ada lagi yang dapat dikembangkan. Kegiatan pengembangan kubis yang dilakukan adalah intensifikasi pertanian dengan rasionalisasi penanaman pada lahan eksisting berupa penanaman yang diutamakan pada kelas kesesuaian lahan S1 seluas 37.2 ha kemudian kelas kesesuaian lahan S2 seluas 38.7 ha dan S3 seluas 102.63 ha. Intensifikasi pertanian yang dilakukan adalah peningkatan indeks panen yang biasanya setahun 2 kali, pada kelas kesesuaian lahan S1 dan S2 dapat ditingkatkan menjadi 3 kali dalam setahun dengan penambahan pupuk, pemilihan bibit unggul, pemberantasan hama dan penyakit.

\section{KESIMPULAN}

Komoditas unggulan utama di Kota Pagar Alam untuk komoditas perkebunan di Kecamatan Dempo Selatan, Dempo Tengah, Dempo Utara dan Pagar Alam Utara adalah kopi robusta. Komoditas unggulan utama tanaman pangan di Kecamatan Dempo Selatan, Dempo Tengah, Dempo Utara dan Pagar Alam Utara adalah padi sawah dan komoditas unggulan utama tanaman hortikultura di Kecamatan Dempo Utara adalah kubis. Lahan yang berpotensi pengembangan untuk komoditas unggulan tanaman perkebunan seluas 7,443.08 ha terdiri dari 3,027.34 ha kelas kesesuaian S2 dan 4,415.74 ha kelas kesesuaian S3. Potensi pengembangan padi sawah seluas 2,350.89 ha terdiri dari 225.82 ha kelas kesesuaian S2 dan 2,125.07 ha kelas kesesuaian S3. Lahan berpotensi pengembangan kubis tidak tersedia.

Hirarki wilayah masing-masing kecamatan adalah Kecamatan Pagar Alam Selatan tergolong hirarki I, Dempo Utara dan Dempo Selatan tergolong hirarki II, Pagar Alam Utara dan Dempo Tengah tergolong hirarki III. Pengembangan komoditas unggulan kopi robusta diarahkan di Kecamatan Dempo Selatan seluas 2,824.26 ha (Prioritas 1), Kecamatan Dempo Utara seluas 1,658.41 ha (Prioritas 2), Kecamatan Dempo Tengah seluas 241.41 ha (prioritas 3) dan Kecamatan Dempo Selatan seluas 206.79 ha (prioritas 4). Pengembangan komoditas unggulan padi sawah diprioritaskan di Kecamatan Dempo Tengah seluas $1,496.13$ ha.

\section{DAFTAR PUSTAKA}

Ameriyani,P. (2014). Perencanaan pengembangan Sub Sektor Perikanan Laut Di Lima Kecamatan Di Kabupaten Rembang.Jurnal Economics Development Analysis. 3(1):225-234

Blakely EJ. 1994. Planning Local Economic Development: Theory and Practice.2nd Edition. California (USA):International Education and Professional Publisher.

Boix LR, Zinck JA. 2008. Land use planning in the chaco plain (Burruyacu; Argentina). Part 1: Evaluating land use options to support crop diversification in an agricultural frontier area using physical land evaluation. Environmental Management. 42: 1043 - 1063.

[BPS] Badan Pusat Statistik Kota Pagar Alam. 2015. Pagar Alam Dalam Angka Tahun 2015. Pagar Alam (ID): Badan Pusat Statistik.

[BBPPSDLP] Balai Besar Penelitian dan Pengembangan Sumberdaya Lahan Pertanian. 2011. Petunjuk Teknis Evaluasi Lahan Untuk Komoditas Pertanian. Bogor (ID): BBPPSDLP Badan Litbang Kementerian Pertanian.

Chiang S. 2009. Location quotient and trade. Annual Regional Science. 43: 339 - 414

[FAO] Food and Agriculture Organization. 1976. A Framework for Land Evaluation. Rome (IT): Soil Bull. No. 32, FAO. 
Lillesand MT, Kiefer RW. 1993. Penginderaan Jauh dan Interpretasi Citra. [Terjemahan]. Yogyakarta (ID) : Gadjah Mada University Press.

Manik, T.R., Adrianto, D.W., Subagiyo,A. 2013. Kajian Pengembangan Kawasan Agropolitan Seroja Kabupaten Lumajang. Jurnal Tata Kota dan Daerah. 5(1):65-76

Nowar, W.,Baskoro,D.P.T.,Tjahjono,B. 2015. Analisis Kesesuaian Lahan Komoditas Unggulan dan Arahan Pengembangannya di Wilayah Kabupaten Cianjur. Jurnal Tata Loka.17(2):87-98.

Ogunlade MO, Aikpokpodion PO, Braimoh AK. 2012. Land suitability evaluation for cocoa production in Nigeria using fuzzy methodology. International Journal of Suitable Crop Production. 7: 13 - 20.

Panuju, D.R., Rustiadi, E. 2013. Teknik Analisis Perencanaan Pengembangan Wilayah. Bogor (ID): Departemen Ilmu Tanah Dan Sumberdaya Lahan IPB

Raharjo, S.,Widiatmaka, Sudadi,U. 2015. Analisis Kesesuaian Lahan Untuk Komoditas Sayuran Unggulan di Kabupaten Batang.Jurnal pengelolaan Sumberdaya alam dan Lingkungan. 5(1):33-41

Setiawati, A.R., Sitorus, S.R.P, Widiatmaka. 2016. Perencanaan Penggunaan Lahan Komoditas Unggulan Perkebunan di Kabupaten Tanah Datar.Jurnal Tata Loka 18(3):131-140

Sitorus, S.R.P.,Mulya,S.P., Iswati,A., Panuju,D.R.,.Iman. L.O.S. 2014.Teknik Penentuan Komoditas Unggulan Pertanian Berdasarkan Potensi Wilayah dalam Rangka Pengembangan Wilayah. Dalam: Astuti,P., Manan, M., Dinata, A., Asteriani, F (Editor). Prosiding Seminar Nasional ASPISustainable and Resilient Cities and Regions, Pekan baru 17-18Oktober2014. Pekanbaru (ID): Universitas Islam Riau hlm 396-406.

Sitorus,S.R.P., Purnamasari, A., Mulya, S.P. 2015. Analisis Keterkaitan Penggunaan Lahan. Rencana Pola Ruang dan Hirarki Wilayah di Kota Cilegon. Dalam: Putra, G.P.A., Sudharsana, M.G., Sukamara, N (Editor). ProsidingSeminar Nasional Tata Ruang dan SPACE II; Denpasar 15-17Oktober2015;Denpasar (ID): Universitas Hindu Indonesia hlm 501-508.

Widiatmaka, Ambarwulan,W.,Sutomo,B.,Hamzah,U.,Warsono.P. 2014. Perancangan Tataguna Lahan Dan Tata Ruang Kawasan Perkotaan Berbasisi Pertanian:Studi Kasus Kota Terpadu Mandiri Transmigrasi Mesuji. Provinsi Lampung. Prosiding Seminar Nasional Multi Disiplin Ilmu.Jakarta 10 Mei 2014. Penyelenggara: Universitas Budi luhur hlm 98-105

Wirosoedarmo,R.,Sutanhaji,A.T.,Kurniati,E., Wijayanti,R. 2011. Evaluasi Kesesuaian Lahan Untuk Tanaman Jagung Menggunakan Analisis Spasial. Jurnal Agritech.31(1):71-78

Yanis, M.N.,Guchi,H.,Sembiring,M. 2014. Evaluasi Kesesuaian Lahan Kabupaten Dairi Untuk Tanaman Kopi Robusta (coffea robusta lindl). Jurnal Agroteknologi.2(4):1464-1478

Yustian, Sudadi,U., Ardiansyah,M. 2014. Arahan Dan Strategi Pengembangan Lahan Sawah Di Wilayah Pesisir Provinsi Kalimantan Barat. Jurnal Tanah dan lingkungan.16(1):31-37 